\title{
Distribution and breeding sites of potential dengue vectors in Kandy and Nuwara Eliya districts of Sri Lanka
}

\author{
P. H. D. Kusumawathie', R. R. M. L. R. Siyambalagoda ${ }^{2}$ \\ The Ceylon Journal of Medical Science 2005; 48: 43-52
}

\section{Abstract}

Entomological investigations were conducted in 26 urban and semi urban areas in Kandy and Nuwara Eliya districts to determine the distribution and breeding sites of potential vectors of dengue, viz., Aedes aegypti Linnaeus and Aedes albopictus Skuse in these areas. Aedes larval surveys were carried out around suspected/ serologically positive dengue fever (DF)/ dengue haemorrhagic fever (DHF) cases in dengue transmission areas, and, in bus depots, government institutions and tyre shops (high risk places for Aedes breeding) in DF/ DHF non transmission areas.

Aedes aegypti and Ae. albopictus were not encountered in the Nuwara Eliya town (altitude $1900 \mathrm{~m}$ ). But, either Ae. albopictus or Ae. aegypti and Ae. albopictus were encountered in all the other localities (elevation $100-1300 \mathrm{~m}$ ). The majority $(96 \%)$ of breeding sites of Ae. aegypti and Ae. albopictus comprised of water storage containers, discarded receptacles and tyres. Breeding sites of Ae. aegypti and Ae. albopictus differed from one locality to another as well as from one time period to another.

This study shows that the areas situated below 1300 m elevation in Kandy and Nuwara Eliya districts are receptive for dengue transmission. Strengthening of DF/
DHF surveillance and control measures in these areas is an urgent need to reduce morbidity and mortality, and the spatial distribution of DF/DHF in the two districts. Since, the breeding sites differed from one period of time to another and from one locality to another, dengue control measures should be planned based on local and current entomological information.

Key words: Ae. aegypti, Ae. albopictus, Kandy, Nuwara Eliya.

\section{Introduction}

Aedes aegypti Linnaeus is important as the primary vector of dengue fever (DF) and dengue haemorrhagic fever (DHF) in tropical countries of the world. Aedes albopictus Skuse is considered as a secondary vector of DF in South East Asia and the Western Pacific (1).

In Sri Lanka, DF was first reported in early 1960 s (2). Since then, sporadic, progressively large and more frequent DF/DHF outbreaks occurred in the country. Over the past 10 years, the morbidity, mortality and the spatial distribution of the disease increased considerably with 15,434 suspected and serologically positive DF/DHF cases and 88 deaths for the year 2004. At present, DF/DHF is endemic in many urban and semi urban areas, and has invaded new areas, making the disease an important public health problem in the country (3). 
Occurrence of seasonal/periodic peaks of DF/DHF in dengue endemic areas and emergence of new foci of transmission in hitherto DF/DHF transmission free areas are important problems faced by the dengue control programme in the country. Information on the distribution of Ae. aegypti and Ae. albopictus and their breeding sites in a particular area would definitely help to täke timely and appropriate preventive and control measures to reduce the morbidity, mortality and the spatial distribution of the disease. This study was carried out to determine the distribution and breeding sites of Ae. aegypti and Ae. albopictus in Kandy and Nuwara Eliya districts of Sri Lanka.

\section{Methods}

\section{Study area}

This study was carried out from January 2003 to December 2004 in the Kandy and Nuwara Eliya districts of Sri Lanka. The study area comprises of plain and hilly areas with a land area of $3,681 \mathrm{~km}^{2}$ and an estimated mid year population of 2.04 million, for the year 2004 (Chief Secretariat, Planning and Monitoring Division, Kandy). According to the Regional Epidemiologists in the Kandy and Nuwara Eliya districts, the Kandy Municipality and the adjoining urbanized areas in the Divisional Director of Health Services (DDHS) areas, namely, Gangawatakorale, Harispattuwa, Kundasale, Pathadumbara, Udunuwara and Yatinuwara are endemic for DF/DHF. The Nuwara Eliya district has reported a few mini outbreaks during the past few years.

\section{Entomological investigations carried out in the area}

Twenty six urban and semi urban areas located at different altitudes in 24 DDHS areas in the Kandy and Nuwara Eliya districts were randomly selected for Aedes larval surveys. In DF/DHF transmission areas in the districts, Aedes larval surveys were carried out around the suspected and serologically positive DF/DHF cases that were notified mainly by the government hospitals. In hitherto DF/DHF non transmission areas, the surveys were carried out in and around bus depots, government institutions and tyre shops (high risk plaies for Aedes breeding) as these institutions reported frequent $A e$ aegypti and Ae. albopictus breeding. During each survey, a minimum of 100 houses within a $200 \mathrm{~m}$ radius around the DF/DHF case or the high risk institution were visited, all possible Aedes breeding sites were examined and 20 larvae from each positive container were collected randomly by pipetting or dipping, depending on the nature of the breeding habitat. If a particular container had less than 20 larvae, all larvae were collected. The larvae were placed in separate containers (one container per one habitat), staged and identified as $3^{\text {rd }}$ and $4^{\text {th }}$ stages using standard keys $(4,5)$. The $1^{\text {st }}$ and $2^{\text {nd }}$ stage larvae were allowed to develop to $3^{\text {rd }}$ and $4^{\text {th }}$ stages, and the pupae to become adults prior to identification. If, Ae aegypti and/or Ae. albopictus were not encountered in a particular area at the first survey, two more surveys at more than 3 month intervals were carried out in the same area. Aedes mosquito density was determined by the Container Index $(\mathrm{CI}=$ percentage of containers positive for Ae aegypti and Ae, albopictus) for Ae. aegypti and/or Ae. albopictus.

Breeding sites of Ae. aegypti and Ae. albopictus were categorized into 5 groups, viz., (1) water storage containers (water storage cemented tanks and iron and plastic barrels), (2) discarded receptacles in the domestic and peridomestic environment (discarded plastic containers, pots, bottles, coconut shells, polythene, metal ware and tins), (3) tyres, 
(4) domestic appliances (refrigerator trays, flower vases and ant traps) and (5) others (eg., bamboo stump, leaf axils, concrete slabs and roof gutters). The relative importance of each category of containers for Ae. aegypti and Ae. albopictus breeding was determined based on the percentage positivity of each type of container for Ae. aegypti and Ae. albopictus breeding.

\section{Results}

Of the 26 study sites, neither Ae. aegypti nor Ae. albopictus was encountered in the Nuwara Eliya town. Ae. albopictus was encountered in Kalapitiya, Kurunduwatta, Hataraliyadda, Madugoda and Panwila. Both Ae. aegypti and Ae. albopictus were reported from the rest of the localities (Fig 1).

Ae. aegypti and Ae. albopictus were encountered primarily in water storage containers in Ambagamuwa, Bulugohotenna, Galagedera, Galaha, Gampola, Hijjapura, Kandy, Madawala, Poojapitiya, Rikillagaskada and Talatuoya; in discarded receptacles in Daulagala, Hataraliyadda and Kalapitiya; and in tyres in Hanguranketha, Hasalaka, Hatton, Madugoda, Pundaluoya and Walapane (Table 1).

In a particular area, the types of breeding sites of Ae. aegypti and Ae. albopictus differ from one period of time to another (Table 2).

Water storage tanks are the most preferred breeding site of Ae. aegypti and Ae. albopictus while discarded receptacles and tyres serve as important breeding sites of the two vector mosquito species (Table 3 ).

In the study sites that were positive for Ae. aegypti and Ae. albopictus breeding, the CI for Ae. aegypti varied from 1 to $75 \%$, with high CI values for Hasalaka (38\%), Hatton (11\%), Madawala (11\%), Pundaluoya (18\%) and Walapane $(75 \%)$. High CI for $A e$. albopictus, were observed in Hasalaka (25\%), Madugoda (15\%), Rikillagaskada (12\%) and Walapane $(100 \%)$ (Table 4).

\section{Discussion}

Dengue and DHF is a disease complex caused by four serotypes of the dengue virus, namely, Dengue 1,2,3 and 4. The disease is transmitted by Ae. aegypti and Ae.albopictus $(1,6,7)$. Thus, natural transmission of DF/DHF depends on the presence of the dengue virus, Aedes vector mosquitoes and a susceptible population.

According to serological studies carried out in Sri Lanka, the World Health Organisation (1985) reported DF in towns that are situated below an altitude of $1200 \mathrm{~m}$ (2). Vitarana (1986) too, reported that dengue was prevalent in areas below the altitude of 1000 $\mathrm{m}$ (8). However, these studies have not sufficiently dealt with the entomological aspects of DF/DHF in these areas. In the present study, Ae. aegypti and Ae. albopictus were encountered even at elevations of 1300 $\mathrm{m}$, making the areas that are situated below $1300 \mathrm{~m}$ receptive for DF/DHF transmission. Also, the density of Ae. aegypti and Ae. albopictus remains high in some areas, especially, Hasalaka, Hatton, Madugoda, Pundaluoya, Rikillagaskada and Walapane, making these areas highly receptive for DF/DHF transmission. Thus, strengthening of DF/DHF surveillance and control measures, specially in urbanized areas situated below $1300 \mathrm{~m}$ elevation is of importance in reducing morbidity, mortality and the spatial distribution of DF/DHF.

In the absence of a specific treatment or a vaccine for DF/DHF, vector control is of 
Map showing the study sites \& occurrance of Ae. aegypti \& Ae. albopictus in Kandy \& Nuwara Eliya Districts

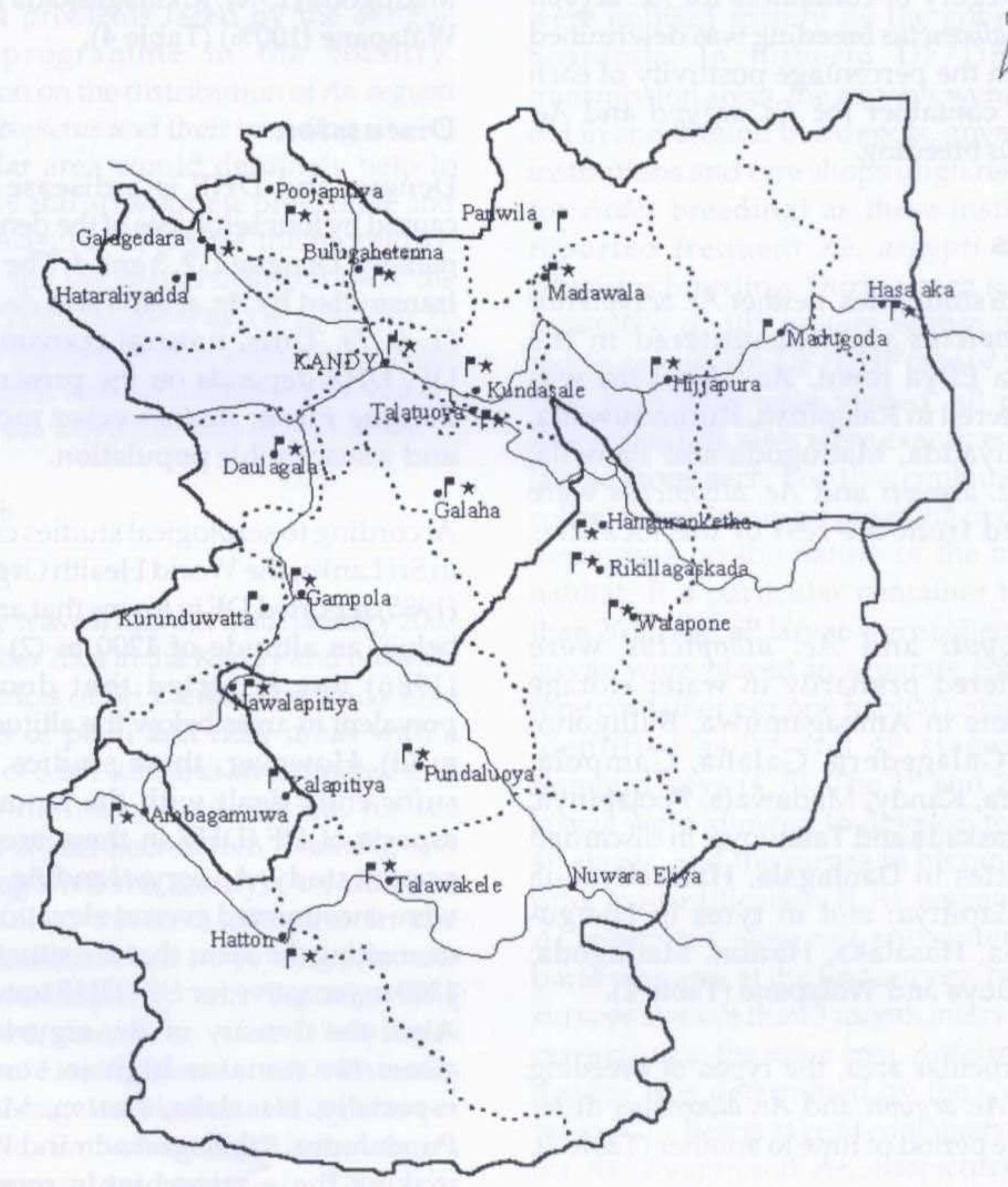

$\begin{array}{ll}\text { - } & \text { Study Sites } \\ & \text { Ae. albopictus } \\ \star \quad A e . \text { aegypti }\end{array}$

Figure 1 
Table 1. Number and \% (given in parentheses) of different types of containers positive for Ae. aegypti and Ae. albopicus in the study sites in Kandy and Nuwara Eliya districts: January 2003 - December 2004.

\begin{tabular}{|c|c|c|c|c|c|c|c|}
\hline \multirow[t]{2}{*}{ DDHS area } & \multirow[t]{2}{*}{ Locality } & \multicolumn{6}{|c|}{$\begin{array}{c}\text { Number }(\%) \text { of containers positive for Ae. aegypti and Ae. albopictus in } \\
5 \text { different container types }\end{array}$} \\
\hline & & WSC & DR & $\mathrm{T}$ & DA & $\mathrm{O}$ & Total \\
\hline Akurana & Bulugohotenna & $24(83)$ & $4(14)$ & $0(0)$ & $1(3)$ & $0(0)$ & $29(100)$ \\
\hline Ambagamuwa & Ambagamuwa & $7(78)$ & $2(22)$ & $0(0)$ & $0(0)$ & $0(0)$ & $9(100)$ \\
\hline Galaha & Galaha & $5(83)$ & $1(17)$ & $0(0)$ & $0(0)$ & $0(0)$ & $6(100)$ \\
\hline Hanguranketha & Hanguranketha & $0 \quad(0)$ & $0(0)$ & $4(100)$ & $0(0)$ & $0(0)$ & $4(100)$ \\
\hline Hanguranketha & Rikillagaskada & $23(55)$ & $10(24)$ & 8 (19) & $0(0)$ & 1 (2) & $42(100)$ \\
\hline Hasalaka & Hasalaka & $0 \quad(0)$ & $0(0)$ & $6(100)$ & $0(0)$ & $0(0)$ & $6(100)$ \\
\hline Hataraliyadda & Hataraliyadda & $2(29)$ & $5(71)$ & $0(0)$ & $0(0)$ & $0(0)$ & $7(100)$ \\
\hline Kotmale & Kalapitiya & $1(25)$ & $2(50)$ & $1(25)$ & $0(0)$ & $0(0)$ & $4(100)$ \\
\hline Kotmale & Pundaluoya & $0 \quad(0)$ & $0(0)$ & $10(100)$ & $0(0)$ & $0(0)$ & $10(100)$ \\
\hline Kundasale & Kundasale & $6(35)$ & $3(18)$ & $8(47)$ & $0(0)$ & $0(0)$ & $17(100)$ \\
\hline Kurunduwatta & Kurunduwatta & $0 \quad(0)$ & $1(33)$ & $2(67)$ & $0(0)$ & $0(0)$ & $3(100)$ \\
\hline Maskeliya & Hatton & $0 \quad(0)$ & $3(17)$ & $14(78)$ & $1(5)$ & $0(0)$ & $18(100)$ \\
\hline MC Kandy & Kandy & $12(53)$ & $9(39)$ & $1(4)$ & $0(0)$ & $1(4)$ & $23(100)$ \\
\hline Medadumbara & Hijjapura & $27(96)$ & $1(4)$ & $0(0)$ & $0(0)$ & $0(0)$ & $28(100)$ \\
\hline
\end{tabular}

${ }^{*} \mathrm{WSC}=$ water storage containers, $\mathrm{DR}=$ discarded receptacles, $\mathrm{T}=$ tyres, $\mathrm{DA}=$ domestic appliance, $\mathrm{O}=\mathrm{other}$ 


\begin{tabular}{|c|c|c|c|c|c|c|c|}
\hline \multirow[t]{2}{*}{ DDHS area } & \multirow[t]{2}{*}{ Locality } & \multicolumn{6}{|c|}{$\begin{array}{c}\text { Number }(\%) \text { of containers positive for Ae. aegypti and Ae. albopictus in } \\
5 \text { different container types }\end{array}$} \\
\hline & & WSC & DR & $\mathrm{T}$ & DA & $\mathrm{O}$ & Total \\
\hline Nuwara Eliya & Nuwara Eliya & $0 \quad(0)$ & $0(0)$ & $0(0)$ & $0(0)$ & $0(0)$ & $0 \quad(0)$ \\
\hline Panwila & Panwila & $1(33)$ & $0(0)$ & $0(0)$ & $1(33)$ & $1(33)$ & $3(99)$ \\
\hline Pasbage & Nawalapitiya & $7(30)$ & $7(30)$ & $8(35)$ & $0(0)$ & $1(5)$ & $23(100)$ \\
\hline Pathadumbara & Madawala & $23(85)$ & $3(11)$ & 1 (4) & $0(0)$ & $0(0)$ & $27(100)$ \\
\hline Pathahewaheta & Talatuoya & $36(80)$ & $5(11)$ & $0 \quad(0)$ & $1(2)$ & $3(7)$ & $45(100)$ \\
\hline Poojapitiya & Poojapitiya & $11(74)$ & $2(13)$ & $0 \quad(0)$ & $2(13)$ & $0(0)$ & $15(100)$ \\
\hline Talawakele & Talawakele & $2(40)$ & $2(40)$ & $1(20)$ & $0(0)$ & $0(0)$ & $5(100)$ \\
\hline Tumpane & Galagedera & $8(67)$ & $4(33)$ & $0 \quad(0)$ & $0(0)$ & $0(0)$ & $12(100)$ \\
\hline Udadumbara & Madugoda & $1 \quad(4)$ & $0(0)$ & $27(96)$ & $0(0)$ & $0(0)$ & $28(100)$ \\
\hline Udapalatha & Gampola & $14(54)$ & $7(27)$ & $2 \quad(8)$ & $1(4)$ & $2(7)$ & $26(100)$ \\
\hline Udunuwara & Daulagala & $2(33)$ & $4(67)$ & $0 \quad(0)$ & $0(0)$ & $0(0)$ & $6(100)$ \\
\hline Walapane & Walapane & $0 \quad(0)$ & $0(0)$ & $3(100)$ & $0(0)$ & $0(0)$ & $3(100)$ \\
\hline
\end{tabular}


Table 2. Number and \% (given in parentheses) of different types of containers positive for Ae. aegypti and Ae. albopictus at different periods of time in three localities in Kandy and Nuwara Eliya districts: January 2003 - December 2004.

\begin{tabular}{|c|c|c|c|c|c|}
\hline \multirow{2}{*}{$\begin{array}{l}\text { Study site } \\
\text { and date }\end{array}$} & \multicolumn{5}{|c|}{ Number (\%) of containers positive for Ae. aegypti and Ae. albopictus } \\
\hline & WSC & DR & $\mathrm{T}$ & Other & Total \\
\hline \multicolumn{6}{|c|}{ Bulugohotenna } \\
\hline 2.1 .2004 & $5(71)$ & $2(29)$ & $0 \quad(0)$ & $0 \quad(0)$ & $7(100)$ \\
\hline 8.11 .2004 & 9 (82) & $2(18)$ & $0 \quad(0)$ & $0 \quad(0)$ & $11(100)$ \\
\hline 10.12.2004 & $8(100)$ & $0 \quad(0)$ & $0 \quad(0)$ & $0 \quad(0)$ & $8(100)$ \\
\hline \multicolumn{6}{|l|}{ Hijjapura } \\
\hline 26.1.2004 & $38(100)$ & $\begin{array}{ll}0 & (0)\end{array}$ & $0 \quad(0)$ & $0 \quad(0)$ & $38(100)$ \\
\hline 21.2.2004 & $3(100)$ & $0 \quad(0)$ & $0 \quad(0)$ & $0 \quad(0)$ & $3(100)$ \\
\hline 22.4 .2004 & 5 (83) & 1 (17) & $0 \quad(0)$ & $0 \quad(0)$ & $6(100)$ \\
\hline 22.10 .2004 & $6(100)$ & $0 \quad(0)$ & $0 \quad(0)$ & $0 \quad(0)$ & $6(100)$ \\
\hline \multicolumn{6}{|c|}{ Selambridge } \\
\hline 7.1.2004 & $4(36)$ & $2(18)$ & $5(46)$ & $0 \quad(0)$ & $11(100)$ \\
\hline 4.2 .2004 & $0 \quad(0)$ & $3(100)$ & $0 \quad(0)$ & $0 \quad(0)$ & $3(100)$ \\
\hline 11.5 .2004 & $3(50)$ & $2(33)$ & $0 \quad(0)$ & $1(17)$ & $6(100)$ \\
\hline
\end{tabular}

*WSC $=$ water storage containers, $\mathrm{DR}=$ discarded receptacles, $\mathrm{T}=$ tyres, $\mathrm{O}=$ other

Table 3. Positivity of different types of breeding sites for Ae. aegypti and Ae. albopictus in Kandy and Nuwara Eliya districts: January 2003 - December 2004.

Habitat

Number (\%) of habitats positive for

\begin{tabular}{lrrr} 
& Ae. aegypti & Ae. albopictus & Total $^{*}$ \\
\hline Water storage containers & $126(62)$ & $108(48)$ & $214(54)$ \\
Discarded receptacles & $25(12)$ & $53(23)$ & $75(19)$ \\
Tyres & $48(24)$ & $52(23)$ & $94(23)$ \\
Domestic appliances & $4(1)$ & $5(2)$ & $7(2)$ \\
Other & $1(1)$ & $8(4)$ & $9(2)$ \\
Total & $204(100)$ & $226(100)$ & $399(100)$ \\
\hline
\end{tabular}

*Total number of containers positive for both Ae. aegypti and Ae. albopictus breeding does not equal to the sum of positive containers for Ae. aegypti and Ae. albopictus due to mixed breeding of the two species in 31containers. 
Table 4. Container index (CI) of Ae. aegypti and Ae. albopictus in different study sites in Kandy and Nuwara Eliya districts: January 2003 - December 2004.

\begin{tabular}{|c|c|c|c|c|}
\hline \multirow[t]{2}{*}{ DDHS area } & \multirow[t]{2}{*}{ Locality } & \multirow{2}{*}{$\begin{array}{l}\text { No.of containers } \\
\text { encountered }\end{array}$} & \multicolumn{2}{|c|}{ No $(\%)$ of containers positive for } \\
\hline & & & Ae. aegypti & Ae. albopictus \\
\hline Akurana & Bulugohotenna & 349 & $22(6)$ & $9(3)$ \\
\hline Ambagamuwa & Ambagamuwa & 75 & $5(7)$ & $4(5)$ \\
\hline Galaha & Galaha & 88 & $3(3)$ & $3(3)$ \\
\hline Hanguranketha & Hanguranketha & 95 & 1 (1) & $3(3)$ \\
\hline Hanguranketha & Rikillagaskada & 279 & $8(3)$ & $34(12)$ \\
\hline Hasalaka & Hasalaka & 8 & $3(38)$ & $2(25)$ \\
\hline Hataraliyadda & Hataraliyadda & 129 & $0(0)$ & $7(5)$ \\
\hline Kotmale & Kalapitiya & 56 & $0 \quad(0)$ & $4(7)$ \\
\hline Kotmale & Pundaluoya & 39 & $7(18)$ & $3(8)$ \\
\hline Kundasale & Kundasale & 234 & 12 (5) & $5(2)$ \\
\hline Kurunduwatta & Kurunduwatta & 96 & $0(0)$ & $3(3)$ \\
\hline Maskeliya & Hatton & 126 & $14(11)$ & $3(2)$ \\
\hline MC Kandy & Kandy & 376 & $18(5)$ & $7(2)$ \\
\hline Medadumbara & Hijjapura & 441 & 40 (9) & $15(3)$ \\
\hline Nuwara Eliya & Nuwara Eliya & 186 & $0(0)$ & $0(0)$ \\
\hline Panwila & Panwila & 70 & $0(0)$ & $3(4)$ \\
\hline Pasbage & Nawalapitiya & 466 & $10(2)$ & $13(3)$ \\
\hline Pathadumbara & Madawala & 149 & $17(11)$ & $10(7)$ \\
\hline Pathahewaheta & Talatuoya & 272 & $18(7)$ & $25(9)$ \\
\hline Poojapitiya & Poojapitiya & 133 & $4(3)$ & $11(8)$ \\
\hline Talawakele & Talawakele & 100 & $4(4)$ & 1 (1) \\
\hline Tumpane & Galagedera & 191 & $4(2)$ & $8(4)$ \\
\hline Udadumbara & Madugoda & 175 & $0(0)$ & $27(15)$ \\
\hline Udapalath & Gampola & 393 & $8(2)$ & $19 \quad(5)$ \\
\hline Udunuwara & Daulagala & 166 & $3(2)$ & 3 (2) \\
\hline Walapane & Walapane & 4 & $3(75)$ & $4(100)$ \\
\hline Total & & 4696 & $204 \quad(4)$ & $226 \quad(5)$ \\
\hline
\end{tabular}


importance in DF/DHF prevention and control where elimination of breeding sites of Ae. aegypti and Ae. albopictus is a priority. Although Ae. aegypti and Ae. albopictus breed in a wide variety of containers, the most preferred breeding sites of these vectors in the study sites were the water storage containers (cemented tanks and iron and plastic barrels), tyres and discarded receptacles. Water storage is a common household practice in the study sites, even in the sites that are situated in the wet zone. Water storage tanks were reported as important breeding sites of Ae. aegypti and Ae. albopictus in other localities of Sri Lanka $(9,10)$, in other South East Asian countries $(11,12)$ and in the Western Pacific (5). Thus, suitable measures have to be taken for elimination of vector breeding in these containers, if DF is to be controlled.

In the study area, the types of vector breeding sites differ from one time period to another and from one locality to another. Hence, DF/ DHF control measures should be planned based on local and current entomological information, targeting the potential breeding sites of Ae. aegypti and Ae. albopictus in the particular areas, in order to achieve effective and efficient DF/DHF control.

Ae. aegypti and Ae. albopictus were not encountered in the Nuwara Eliya town (elevation $1900 \mathrm{~m}$ ) in the present study. With the global warming, increase in temperature and less rainfall is expected at high elevations in the Nuwara Eliya district (13). This may create suitable habitats for $A e$. aegypti and Ae. albopictus breeding at elevations higher than $1300 \mathrm{~m}$. Thus, regular and long term entomological investigations in these areas would help to detect such areas early and to take timely remedial measures in order to prevent DF/DHF transmission in these areas.

\section{Acknowledgements}

The authors wish to thank Dr. L. B. H. Denuwara, the Deputy Provincial Director of Health Services, Kandy, for the support given for the field activities of the study. The Entomological Assistant, Mr. M. M. Raafi helped in entomological investigations, and Mrs. Swarna Seneviratne (Staff Technical Officer) and Mrs. Nimali Piyatissa (Technical Officer), Department of Geography, University of Peradeniya, helped in the preparation of the map. We thank them too for their kind assistance.

\section{References}

1. World Health Organization. Chemical methods for the control of vectors and pests of public health importance. In: Chavasse D.C, Yap H.H, eds. WHO/ CTD/WHOPES/ 97.2, 1997; 16.

2. World Health Organization. Arthropod -borne and rodent-borne viral diseases. Report of a WHO Scientific Group, Technical Report Series, 719, Geneva. 1985; 32.

3. Ministry of Health, Sri Lanka. Framework for plan of action for prevention and control of dengue fever in Sri Lanka. Draft prepared by the Epidemiology Unit, Ministry of Health, Colombo. 2005; 1-24.

4. Barraud P.J. The fauna of British India, Vol V. London, Taylor and Francis. $1934 ; 138-143$.

5. World Health Organization. Guidelines for dengue surveillance and mosquito control. Western Pacific education in action Series No. 8, WHO Regional Office for the Western Pacific, Manila. 1995; 5-15.

6. Hapugoda M.D., Gunasekera M.B., de Silva N.R., Gunasena S., Prithimala L.D., Dayanath M.Y.D. and Abeyewickreme 
W. Detection of dengue virus in Aedes albopictus mosquitoes by Reverse Transcription Polymerase-Chain Reaction-Lipid Hybridization (RT-PCR$\mathrm{LH}$ ) based assay. The Bulletin of the Sri Lanka College of Microbiologists. 2003; $1(1): 30-31$.

7. Hapugoda G.P.G., de Silva N.R. and Abeyewickreme W. Breeding of Aedes aegypti and Aedes albopictus in some dengue endemic areas. Sri Lanka College of Microbiologists, Annual Academic Sessions. 2000; Abstract no.4.

8. Vitarana T., Herath P., Kalpage K., Jayasekera N., Wickramasinghe M. and Gunatilake V.Study of mosquito borne diseases in some new irrigation schemes in Sri Lanka, with particular reference to filariasis and arboviral diseases. Proceedings of the workshop on irrigation and vector borne disease transmission. International Irrigation Management Institute. 1986; 9-13.

9. Kusumawathie P.H.D. and Fernando W.P. Breeding habitats of Aedes aegypti Linnaeus and Ae. albopictus Skuse in a dengue transmission area in Kandy, Sri
Lanka. Ceylon Journal of Medical Science. 2003; 46: 51-60.

10. Yapabandara A.M.G.M. and Abeykoon A.R. Aedes aegypti and Ae. albopictus breeding sites in the Matale Municipal Council area. Sri Lanka Association for the Advancement of Science, Proceedings of the 58 th Annual Session, 2002; 20.

11. Manual on entomological surveillance of vector borne diseases, eds: Rahman S.J., Sharma S.K., Rajagopal R. National Institute of Communicable Diseases. Ministry of Health and Family Welfare, New Delhi, 1989; 82-89.

12. Sharma S.K. Entomological investigations of a dengue fever outbreak: experience from rural areas of Haryana, India. Dengue Bulletin. 1998; 22: 36- 39.

13. Wijesundera M.de.S., Herath H.M. S.S.D., Rajapakse L.C., de Alwis R.W. and Fernando H. M. Initial subsectoral draft on national action plan on climate change and health - Sri Lanka. Ministry of Forestry and Environment, Sri Lanka, $1998 ; 3-22$. 